\title{
MANUAL QUIRÚRGICO
}

\section{Juan V. Fernández de la Gala}

FEDERICO RUBIO y GALÍ, Manual de clínica quirúrgica (1849-1850) (edición facsímil y notas introductorias de J. L. Carrillo y J. R. Cabrera), Cádiz, Universidad de Cádiz, 2002, 244 pp.

Coincidiendo con el centenario de la muerte del Dr. Federico Rubio y Galí (1827-1902), se reedita en edición facsímil esta obra de juventud del ilustre cirujano. Compuesto cuando Rubio aún era alumno en la Facultad de Medicina de Cádiz, el Manual de Clínica Quirúrgica constituye una verdadera rareza bibliográfica, ya que hasta la fecha sólo se han localizado tres ejemplares de la edición original. El primero de ellos, procedente de la biblioteca personal del profesor Orozco Acuaviva, ha servido para confeccionar esta edición facsímil. Los otros dos han podido ser hallados después de larga pesquisa en la Real Academia de Medicina de Madrid y en la biblioteca de la Universidad Complutense.

Nacido en El Puerto de Santa María (Cádiz), el doctor Federico Rubio constituye una figura clave de la medicina española del siglo XIX. Cirujano ilustre, comprometido ideológicamente con el krausismo y la causa republicana, sus convicciones políticas le obligaron a abandonar el país en varias ocasiones. Es precisamente en su exilio itinerante entre Londres, París y Montpellier donde conoce de primera mano las novedades médicas de una Europa algo más civilizada que la España moji-

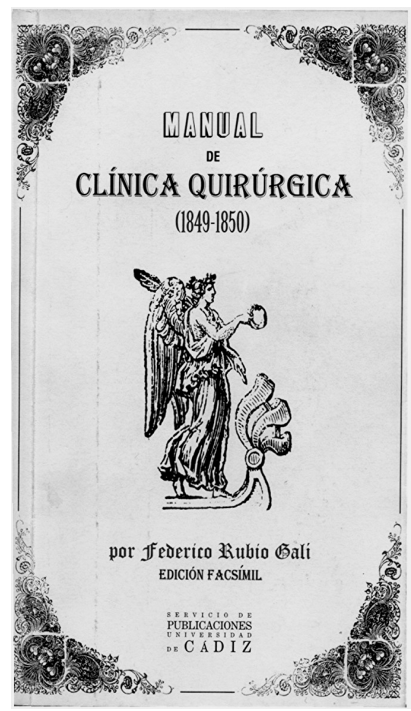
gata de entonces.

La cirugía europea vivía tiempos de conquista. Desde 1846 el éter y el cloroformo marcaron el comienzo de la redención frente al dolor y la posibilidad de realizar intervenciones quirúrgicas más prolongadas y menos cruentas. La higiene elemental de las manos del cirujano, el uso regular del vapor de agua para esterilizar el instrumental quirúrgico, así como las pulverizaciones de ácido fénico, permitían ya mantener a los microorganismos a raya y habían logrado disminuir significativamente la mortandad en el quirófano.

Por otra parte, la lucha de la Medicina contra el cáncer contaba entonces sólo con la cirugía como procedimiento drástico para atajar el mal. Federico Rubio conoció de primera mano las nuevas intervenciones que empezaban a realizarse en Europa y las popularizó en nuestro país. Así, en 1860 , los cirujanos españoles más conservadores pudieron asistir, un poco incrédulos, a la primera extirpación de ovario y un año después a la primera histerectomía. Federico Rubio demostrará también ante sus ojos que, en caso necesario, era posible extirpar sin graves riesgos un riñón o incluso el conducto laríngeo, tal como hiciera ya el propio Billroth pocos años antes. 


\section{LIBROS}

Después de fundar en Sevilla la Sociedad de Medicina Operatoria y la Escuela Libre de Medicina y Cirugía — germen de lo que hoy es la Facultad de Medicina - su compromiso político le llevó probablemente más lejos de lo que él mismo hubiera deseado. Tras la Revolución de 1868, fue diputado electo por Sevilla a las Cortes Constituyentes y más tarde senador y embajador de España en Londres. Bajo el reinado de Alfonso XII, instalado ya definitivamente en Madrid, Federico Rubio abandonó toda actividad política para dedicarse por entero a la práctica hospitalaria. $\mathrm{Su}$ fama estaba ya tan asentada que, incluso a sabiendas de sus firmes convicciones republicanas, el propio rey acude a él esperanzado ante la enfermedad que consumía irremediablemente a la reina Mercedes. Crea por entonces su obra más recordada: el Instituto de Terapéutica Operatoria, en cuyo seno fundaría también la Escuela de Enfermeras de Santa Isabel de Hungría, pionera en nuestro país. Primero como dependencia del Hospital de la Princesa y luego como edificio propio, el Instituto Rubio constituye un referente obligado en la historia de española de las especialidades, un lugar donde fue posible aunar la formación médica de vanguardia, la preocupación social y la labor asistencial más actualizada.

Aparte de una rareza bibliográfica, el Manual de Clínica Quirúrgica de Rubio es un libro doblemente enigmático. En primer lugar porque todos los ejemplares encontrados nos muestran una obra incompleta, que se interrumpe inexplicablemente en la página 244, en mitad de una palabra, quedando aún por abordar toda la tercera parte del proyecto anunciado. $\mathrm{Y}$ en segundo lugar porque, de modo también inexplicable, Federico Rubio eludirá mencionar esta obra de juventud en sus memorias.

Desde luego - y tal como apunta el profesor Carrillo en la introducción — para explicar su carácter de edición inconclusa, bruscamente interrumpida, parece razonable buscar la causa en el seno de la empresa editorial a la que fue asignada: la imprenta de José María Ruiz, muy próxima a la Facultad de Medicina. En los fondos del Archivo Municipal de Cádiz he podido comprobar que el local de la imprenta Ruiz (Plaza de las Viudas, $\mathrm{n}^{\circ} 100$ ) pasó a convertirse en una vivienda común en febrero de 1850. Así pues, la actividad comercial de la imprenta Ruiz desaparecería bruscamente de la ciudad a comienzos de ese mismo año, cesando también por entonces la publicidad que regularmente figuraba en los medios escritos. Los catálogos bibliográficos consultados no recogen tampoco obras de la imprenta Ruiz posteriores a esta fecha. Parece entonces que el Manual de Clínica Quirúrgica de Federico Rubio sería el último (e inacabado) trabajo editorial de la empresa Ruiz.

En este supuesto, no resulta extraño que se advierta cierta premura en la confección de las páginas finales del libro, particularmente defectos de impresión, caída accidental de tipos, que el cajista recompone de modo apresurado e inexperto, cambios en el diseño y en la numeración de pliegos y páginas y en la subordinación de epígrafes y apartados. Un trabajo, en fin, poco profesional que, a juzgar por la sucesión de varios patrones ortográficos (existen fenómenos intermitentes de ceceo y seseo muy llamativos), pudo quedar temporalmente en manos de personal subalterno poco cualificado y libre de la supervisión del jefe de taller o del propio autor que, sólo en ocasiones, se ocuparían de revisar la transcripción de los originales.

Aún más enigmático resulta el silencio de Rubio respecto al Manual, eludiendo cualquier mención a esta obra en el index operum de su cosecha. ¿Cuál podría ser la causa? Personalmente, entiendo que Federico Rubio no se considerase a sí mismo como el autor estricto de esta obra, que es más bien un concierto de influencias, donde la voz de los autores consagrados y la de sus propios profesores tendrían un peso mucho más decisivo que la suya propia. Si en otras obras de Rubio se advierte un sello de originalidad característico, en esta primera, salvo puntuales aportaciones, su trabajo es el de recopilador de las experiencias y los conocimientos de otros.

Dado que Federico Rubio era aún estudiante del último curso cuando confeccionaba este $M a$ nual, parece también muy probable que tuviera que sufrir las críticas de algunos compañeros, que 
lo tachasen de osado, de pretencioso y hasta de plagiario. Ya desde el prólogo se apresura a atajar estas críticas con una vehemencia quizá desmedida, lo que pudiera indicar que este tipo de comentarios se produjeron realmente: «Si la envidia, enmascarada con el nombre de noble emulación, dijese que mi obra es un plagio, yo pediría que me citasen el tratado de clínica quirúrgica con cuyas plumas me engalano (...) no espero que exista un cerebro tan necio que me dirija el antedicho cargo» (p. IX). Desde mi punto de vista, las duras palabras de Federico Rubio tienen un claro destinatario. Leyendo entre líneas se adivina que las acusaciones proceden de algún compañero de su mismo nivel académico en el que pudiera surgir «la envidia, enmascarada con el nombre de noble emulación».

La amistad de Federico Rubio con Imperial Iquino Caballero, hijo de un catedrático de la Facultad y compañero de su promoción, estuvo siempre teñida de cierta competitividad académica. En Mis maestros y mi educación, deliciosa autobiografía de sus primeros años, puede seguirse estrechamente la evolución de la amistad entre Rubio e Iquino, que se inicia con la admiración mutua y se pierde luego en los laberintos de una rivalidad amarga y poco afortunada. Imperial era probablemente el alumno más brillante de la promoción. Ambos compiten en 1845 por el puesto de ayudante de disector, plaza que se concede inicialmente a Iquino, según sugiere Rubio por presiones de su padre desde la cátedra. Dos días después, por mediación del director de trabajos anatómicos D. Vicente Domínguez — que conocía bien la habilidad disectora de Rubio - se revoca la decisión y se designa a Federico Rubio para ocupar dicho cargo. Desde entonces ambos amigos se distancian seriamente.

A mi juicio, el incidente convierte a Imperial Iquino en sólido candidato para ser el autor airado de estas acusaciones de plagio que, veladas o manifiestas, debieron de haber mortificado bastante a Rubio. En este sentido considero que resultan muy sugestivos algunos diálogos que el autor reconstruye en sus memorias: «iCalla, calla! —repuso Iquino-. Extrañaría que no salieses con alguno de tus plagios» (Mis maestros y mi educación p. 267). Este comentario, expresado con visos de literalidad, pero en realidad reconstruido muchos años después por Rubio, tiene aún más valor que si fuese escrupulosamente literal, pues muestra el modo en que Federico Rubio rememora su resentida relación con Imperial Iquino, destilando en un par de frases la esencia de las suspicacias de uno y un cierto rescoldo de rencor del otro.

Dejando a un lado sus aspectos más agrios, sin duda el Manual está lleno de elementos mucho más alentadores, que apuntan ya la futura personalidad de Rubio. A pesar de su juventud (contaba escasamente 22 años al escribir esta obra), se advierten en él una rara habilidad pedagógica y una suerte de didactismo ameno que no sólo pueden atribuirse a la peculiaridad de su carácter, sino también al deseo consciente y cabal de hacerse entender por todos. El humor, desde la fina ironía al chiste franco, es uno de estos recursos didácticos y está presente a lo largo de toda la obra. El profesor Laín Entralgo hablaba del «gracejo» como tendencia de estilo de una época y desde luego Rubio no fue una excepción. Por ejemplo, respecto a la dificultad que entraña la exploración de la trompa de Eustaquio escribe: «dicen los autores que, tapadas las narices y la boca del enfermo, se le ordene hacer una fuerte espiración (...); yo lo he dispuesto así algunas veces y sólo obtuve ver muy rojo al individuo que lo hizo» (p. 174). En este mismo tono humorístico, no exento a veces de fina sutileza, Rubio pondera el uso de la imaginación en la práctica clínica, pero tiene buen cuidado de recomendar encarecidamente a los principiantes en el ejercicio clínico que se abstengan de ella, de momento (cf. pp. 15-16).

Con socarrona indignación, critica el uso que algunos autores clásicos hacen del sentido del gusto como procedimiento diagnóstico. Los médicos, dice en tono airado, «no deben hacer cosas que rebajen su dignidad, dando origen a que los llamen escatófagos. Ni aun en la diabetes es preci- 


\section{LIBROS}

so gustar la orina, porque la química mostrará los materiales sacarinos mejor que la lengua más perita» (p. 11).

Además de este recurso moderado al humor y la referencia a casos clínicos personales para mitigar una exposición que de otro modo podría tomar un cariz demasiado enciclopédico y farragoso, Rubio emplea otros recursos didácticos. Son constantes las metáforas y ejemplos, no desdeña la pregunta retórica e incluso hace un uso decidido de las onomatopeyas («un run-run», «una especie de glu-glu», etc.) En este mismo sentido, y como referencia clara de tamaño para las lesiones de piel y mucosas, utiliza las monedas habituales que por entonces se encontraban en circulación: un real de plata para las placas circulares del herpes, un realillo, que es el tamaño que pueden llegar a alcanzar las úlceras en la estomatitis aftosa, o medio duro para las placas del eritema centrífugo.

A pesar de tratarse de una obra que se nutre de numerosas fuentes, cabe señalar en el Manual algunas aportaciones originales del Dr. Rubio. En este sentido el autor demuestra ya un conocimiento propio de lo que solemos llamar «psicología de cabecera». Es decir, amén de su campechanía - de la que existen numerosos testimonios - se intuye en sus palabras una habilidad empática buscada y consciente en el trato con el enfermo, como medio para sacar el máximo partido de la anamnesis (Cf. pp. 28-29).

Nos llama igualmente la atención cómo Rubio sugiere ya la confección de un espéculo laríngeo «compuesto de varias facetas que reflejaran la imagen de la glotis a un punto donde pudiera ser vista» (p. 222), un antecedente del laringoscopio - cinco años antes de su invención por Manuel García - digno de ser valorado por los historiadores de la otorrinolaringología.

Del mismo modo, preconiza el uso de la aguja de acupuntura en la exploración de los tumores (p. 80) o refiere experimentos personales en el cadáver sobre la práctica de la percusión craneal para detectar posibles fracturas del cráneo y sugiere la extensión de esta técnica, habitual en el ámbito forense, también al sujeto vivo (p. 129, nota 2). No obstante la sugerencia exploratoria más espectacular quizá sea el uso de un naipe de la baraja para detectar si existe lesión pulmonar en las heridas penetrantes del tórax (pp. 242-243), casi como quien describe un ejercicio de prestidigitación.

Refiere también, como recurso, algunos casos curiosos extraídos del anfiteatro o de su incipiente práctica clínica: un aneurisma del tronco braquiocefálico (pp. 240-241), un caso desproporcionado de parotiditis con muerte por asfixia (p. 216) y un raro caso de hipertrofia congénita del tarso palpebral (p.138). Incluye asimismo la discusión de un caso autópsico de interés: una herida perforante craneal por disparo suicida que, contrariamente a las teorías de «Gall y sus secuaces» permitió durante unas horas conservar al paciente la vida y las funciones del habla (p. 134). Desde nuestra perspectiva actual, la crítica de Rubio no parece muy afortunada, pues lo único salvable de la frenología de Gall — junto a Spurzheim y otros «secuaces»- fue precisamente la localización aproximada del centro del habla, que Broca y Wernicke confirmarían luego y precisarían anatómicamente.

Los galicismos son muy abundantes a lo largo de todo el texto y demuestran la preeminencia de la bibliografía francesa no sólo en la documentación utilizada por Federico Rubio sino, en general, en la enseñanza de la cirugía en casi todo el siglo XIX. Esta situación, valorada por Rubio como una «vergonzosa tutela que en las ciencias nos han impuesto los extranjeros» la esgrime como uno de los motivos que le han apremiado a publicar esta obra. Entre los numerosos galicismos destacan algunos muy flagrantes: "garantidos» (del fr. garantis) por garantizados o respaldados, «rambersado» (del fr. renversé) por volcado, «aeriano» (del fr. aérien) por aéreo o «gotiera» (del fr. gouttière) en lugar de canal, entre otros muchos. Probablemente el más curioso sea la expresión «báculo de la aorta» en vez de la más usual entre nosotros de «cayado de la aorta». También en la bibliografía francesa se acostumbra a utilizar el término más pretencioso de «crosse» (báculo de obispo) en lugar del humilde «houlette» (cayado de pastor) para hacer metafórica referencia al arco aórtico. 
Desconozco si el propio Rubio abordó la traducción de los textos (hay testimonios de su buen dominio del francés), pero me inclino a pensar que más bien haría uso de las numerosas traducciones que ya circulaban en nuestro país, probablemente poco rigurosas y que, plagadas de este tipo de galicismos, contaminarían también la obra de Rubio.

Por último, en el prólogo original, Rubio no deja lugar a dudas sobre sus dificultades económicas: "carezco de mesadas que me costeen la carrera; desde el segundo curso la he seguido con el fruto de mi humilde, pero honesto trabajo». Su padre, don José Rubio y Lubet, había sido desterrado e inhabilitado como letrado por su excesiva simpatía con la causa liberal, lo que sumió a la familia Rubio en el naufragio económico. La propia vocación médica de Federico Rubio fue más un dictado de la necesidad que un reflejo de sus inclinaciones personales: como resultaba muy gravoso para el presupuesto familiar de los Rubio enviar al hijo a Sevilla a estudiar Leyes, el joven Federico tuvo que optar por matricularse en el preparatorio de Medicina en la cercana ciudad de Cádiz. A fin de lograr algún ingreso extra, Rubio alternó sus estudios, primero, con el cargo de profesor de esgrima, en el Colegio de San Felipe Neri, y, luego, trocando florete por bisturí, con la antedicha plaza de disector. Probablemente la publicación de estas páginas hubiera garantizado al joven Rubio unos ingresos bastante esperanzadores en su maltrecha economía de estudiante. Debemos pensar, por tanto, que Federico Rubio tenía motivos

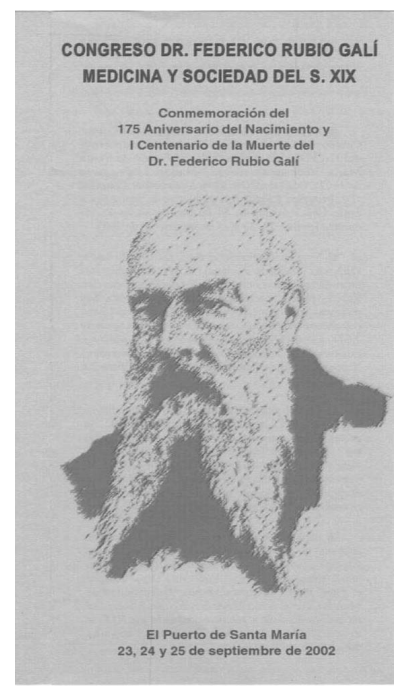
suficientes para dejar caer el peso del olvido sobre un proyecto frustrado que no puede contarse entre sus obras completas, precisamente por incompleta. Un árbol seco en la fructífera cosecha de Federico Rubio.

El doctor Federico Rubio y Galí murió en Madrid el 31 de agosto de 1902, casi la misma noche de su cumpleaños. Este azar de las fechas hace que hayan coincidido el 175 aniversario de su nacimiento y el centenario de su muerte. Ojalá que esta conmemoración no se quede en el simple festejo de una efemérides más y llegue a dar tan hermosos frutos como la reedición, oportuna y entusiasta, de este curioso Manual de Clínica Quirúrgica que, cumpliendo la iniciativa del profesor Orozco, los profesores Carrillo y Cabrera ponen hoy felizmente en nuestras manos. 